\title{
Testing for Multiple Types of Marginal Investor in Ex-Day Pricing
}

\author{
Jan Bartholdy \\ Aarhus School of Business, Denmark \\ Kate Brown \\ University of Otago, New Zealand
}

\begin{abstract}
The observed changes in share prices at the ex-dividend day have led researchers to look for a single marginal investor, either a long or a short term trader with different tax status, dominating all trades to explain the ex-day pricing in different markets. This paper provides a model which extends this research in three directions. One, it allows for the possibility that different types of traders may influence different stocks, thereby generating a separating equilibrium. Two, it identifies an additional marginal investor who has the option of being taxed as a short term or long term trader. Three, it explicitly models the fact that it can take a considerable time from when a dividend based trade is made until taxes have to be paid on that trade. A unique data set from New Zealand is used for the empirical analysis. Evidence of a separating equilibrium with at least two types of marginal investors is found (JEL: G10, G35).
\end{abstract}

Keywords: dividends, ex-day pricing, taxation.

\section{Introduction}

The finance literature contains extensive empirical evidence that share prices fall by an amount less than the dividend per share on the day the stock goes ex-dividend. The search for an explanation for this phenomenon has focused on identification of one type of marginal investor that dominates trades in all stocks. Three types of marginal investors have been suggested. The first type of marginal investor, often referred to as long term investors, faces different taxes on dividends and 
capital gains. ${ }^{1}$ The second type of marginal investor, referred to as short term or professional investors, faces the same tax rate on dividends and capital gains. ${ }^{2}$ The third type of marginal investor is corporate investors who act as dividend captures. ${ }^{3}$ The early papers (referenced in footnotes 1 and 2) all suggest that all trades are dominated by one type of investors whereas Boyd and Jagannathan (1994) and Koski and Scruggs (1998) suggest the existence of a separating equilibrium with two or three types of traders trading in different classes of shares. Koski and Scruggs analyze trading around ex-days and abnormal trading volume by security dealers and find some abnormal trading by dividend captures but little evidence of long term traders exposed to different tax rates.

This paper extends the existing literature on ex-day pricing in three different ways. First, it extends the traditional model used to test for tax effects in ex-day pricing to account for differences in timing between ex-day trading and payment of associated taxes. In the traditional models it is assumed that both dividend and capital gains taxes are paid on the ex-day, whereas in this model explicit account is taken for differences in timing. Depending on the tax system this timing difference may be up to two years. Secondly, the model introduces a new (to the literature) marginal investor and allows for a separating equilibrium representing three different marginal traders: professional short term traders who pay income tax on dividends and capital gains and can deduct losses; long term traders who pay different dividend and capital gains tax, and a (new) mixed trader who can choose whether to be taxed as a short or long term trader. Finally, a novel empirical methodology is used to test for the existence of a separating versus dominating equilibrium and the identity of the marginal investors.

Most prior tests of the hypotheses relating to ex-dividend day pricing behavior have only had access to data sets of either taxable dividends or non-taxable dividends and focused on one type of marginal investor. The data set used in this paper is unique since it contains individual companies whose dividends were taxable or non-taxable depending on the source of the funds supporting the dividend. This tax difference

1. Elton and Gruber (1970), Eades et al. (1984), Brown and Walter (1986), Chui et al. (1992), Barclay (1987), Robin (1991), Michaely (1991), Hearth and Rimbey (1993), Michaely and Murgia (1995) and Bartholdy and Brown (1999).

2. Kalay (1982), Lakonishok and Vermaelen (1983), Booth and Johnston (1984) and Heath and Jarrow (1988).

3. Boyd and Jagannathan (1994). 
allows for powerful tests of tax effects and of marginal investors. In New Zealand, between 1982 and 1985, some companies issued both taxed and non-taxed dividends on a regular basis. Further, the tax rules allowed individuals to choose their tax status with regard to capital gains, leading to the creation of an option. Finally, short selling was not permitted during this period. The unique combination of tax treatments makes it possible to test whether different types of marginal investors affect the pricing of different stocks, i.e. a separating equilibrium, or one type of marginal investor dominating all stocks, i.e., a dominating equilibrium. The results support a separating equilibrium with two types of marginal investors: a long term investor and a mixed trader.

Bartholdy and Brown (1999) use an equivalent dataset to test for tax effects in New Zealand but do not take into account the timing of payment of taxes that in some circumstances can be up to two years after receiving the dividends, nor that different marginal investors may affect trades in different stocks.

The remainder of this paper is organised as follows. Section II contains a brief description of the taxation of dividends and capital gains in New Zealand. In section III the tax regime is modelled more formally. Section IV contains a discussion of the data used in the study. Sections V and VI test for a dominating and separating equilibrium respectively and section VII concludes the paper.

\section{Institutional Setting in New Zealand from 1982 to 1985}

The New Zealand Income Tax Act of 1976 provided for both taxable and non-taxable dividends. If dividends were distributions of capital reserves from, for example, realised profits on the sale of asset, then they were tax free. Otherwise, dividends were taxed as income to the individual investor. This taxation regime lasted until 1985 after which strong restrictions were imposed on the issue of tax free dividends. Until 1985 the same company could issue both taxable and non-taxable dividends on the same day.

Another unique feature of the New Zealand tax regime was the taxation of capital gains. The tax-code differentiated between long term (passive) buyers with zero capital gains tax and short term (active) buyers who faced taxation on capital gains. Differentiation was based on the intention of the purchaser at the purchase date. If the shares were bought for long term gain as an investment, there were no taxes on gains 
and losses could not be deducted. If the shares were bought for the purpose of trading in an active portfolio, any gain on the sale was taxable and losses could be deducted. ${ }^{4}$

Under the tax code it is possible to identify three types of marginal investors: passive or long term, active or short term, and mixed. Long term investors who did not actively trade could safely avoid taxation on capital gains, but were not able to deduct losses. Short term investors who traded all the stocks in the portfolio regularly were taxed on capital gains and dividends, but were able to deduct losses. Mixed investors maintained two portfolios: one active trading portfolio where all the stocks were traded regularly and one passive portfolio were stocks were purchased for long term gain.

Mixed traders could buy the stock cum-dividend with the option of holding the stock for long term gain, taxed as a passive trader, or selling it on the ex-day for short term taxable profits, taxed as a short term trader. As long as the investor had in the past engaged in transactions for the purpose of short term gains, it would have been reasonably easy to argue to the tax authorities that the purpose of the trade was short term profit. Alternatively, if the investor decided to hold the stock in his/her investment portfolio, it could be justified as a tax exempt long term investment.

Thus, the tax status of the capital gains was determined by the investor's ability to convince the tax department of the status of the individual transactions. An investor's choice depended on the relative values of the total after-tax expected gains. In practice, most small private investors were classified as passive or long term investors whereas institutional investors were classified as active or mixed. If the institutional investor maintained two sets of books; a "passive book" and an "active book," then, when buying a stock cum-dividend, these traders had the option of selling the stock when it went ex-dividend (and record the transaction in the "active book") and be taxed as an active trader or holding the stock (and entering it in the "passive book") and be taxed as a passive trader.

During the period up to 1985 short selling was not allowed in New Zealand making it difficult for one type of investor to dominate all trades.

For most investors in New Zealand, the tax year ended on March 30, with tax returns filed in June or July depending on sources of income.

4. As far as the authors can ascertain, New Zealand was the only country with this combination of tax laws. 
For salary earners the most common situation was that any taxes payable were not due until February in the following year. For tax payers with significant non-salary income, such as dividend and capital gain income, provisional tax based on the prior year's tax liability/short fall was paid during the year. As a result of the timing of the payments, an investor engaging in trading around ex-dividends may not have taxes due for nearly two years after the transaction. The current year's provisional tax was independent of the current investment decision. This arrangement meant that the purchase and sale of shares in April, for example, generated tax effects that were not payable for nearly two years.

Boyd and Jagannathan (1994) suggest three classes of traders based on different treatments under the tax code. For the U.S. they suggested taxable individuals, tax-advantaged dividend captures, and tax-neutral arbitrageurs. Taxable individuals are similar to passive investors and tax-neutral arbitrageurs are similar to active investors, with some qualifications. The suggestion of dividend capture, in which corporate investors were able to deduct all or part of the dividend income received from investment in the shares of other companies, was considered. ${ }^{5}$ However, an examination of the accounts of listed companies revealed that the majority of the largest companies in New Zealand never received dividend income from investments, suggesting that dividend capture was not a feature of corporate strategy, at least among the listed firms. This group of investors was not analyzed further.

For the period of this paper, 1982 to 1985, the shares were traded on the New Zealand Stock Exchange in Auckland which was organised as an "open auction market". The bid and ask prices were called out from the floor and recorded on a large black board by runners. Transactions costs were on a sliding scale ranging from $2.5 \%$ to $1 \%$ depending on the size of the transaction.

\section{The General Model}

The expected payoff at the time of purchase from investing in a stock is equal to the expected capital gain minus taxes plus dividends. These cash flows occur at different times so it is necessary to use present values to account for the time value of money.

5. New Zealand had a one hundred percent deductibility of intercorporate dividends in the relevant time period. 


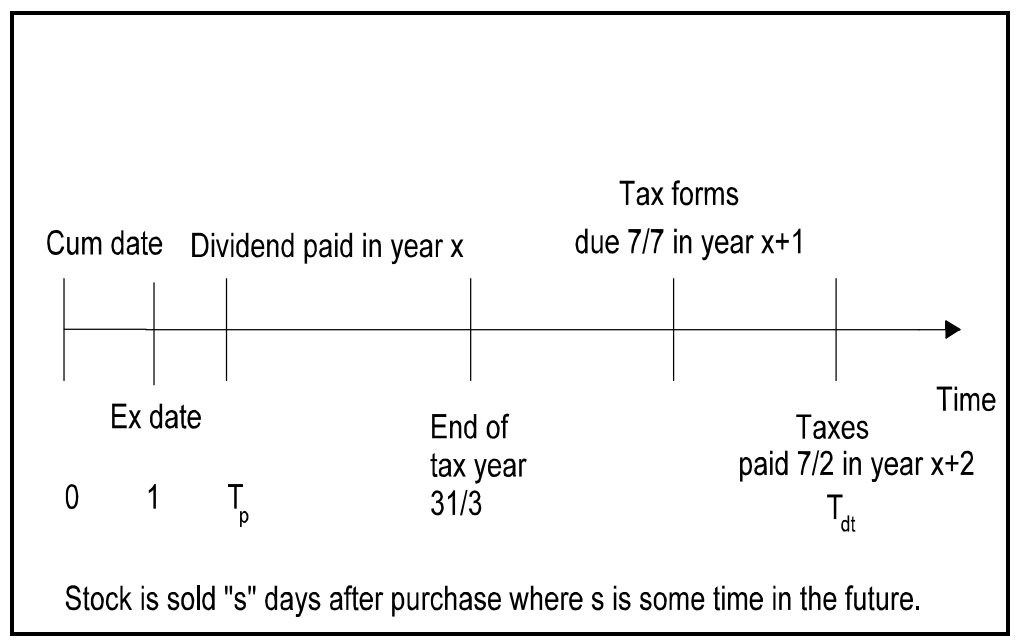

FIGURE 1.- Taxation Time-line for Shares with Taxable Dividends

The general situation is shown in figure 1 . An investor can buy the stock with dividends on the cum-day, $t_{0}$, or without dividends on the ex-day, $t_{1}$. The actual dividends are received $T_{p}$ days later. However, taxes on the dividends are not due until $T_{d t}$ days after the cum-day which may be up to nearly two years. These large time differences necessitate careful attention when calculating the present values of the cash flows to evaluate the various trading strategies. The net present value of the three cash flows from investing in a stock; dividends and dividend taxes, capital gains tax and the final sales price, are discussed below.

Dividends and Dividend Taxes

Dividends are not received on the ex-day, but $T_{p}$ days later. The amount of the dividend has to be discounted back to time zero (cum-day):

$$
D^{T}+D^{N T}=\left(D_{t_{p}}^{T}+D_{t_{p}}^{N T}\right) e^{-T_{p} r_{f}}
$$

where $D_{t_{p}}^{T}$ and $D_{t_{p}}^{N T}$ are respectively taxable and non-taxable dividends paid at $t_{p}, r_{f}$ is the risk free rate of interest, $D^{T}$ is the present value of the taxable dividends and $D^{N T}$ is the present value of the non-taxable dividends paid at time $t_{p}$. 
Subsequent income taxes on dividends are not due until $T_{d}$ days after the purchase of the stock. As indicated above, in New Zealand this may take up to two years. The present value of the future dividend tax is:

$$
\tau_{d} D^{d t l}=\tau_{d} D_{t_{d t}}^{T} e^{-T_{d t} r_{f}}
$$

where $\tau_{d}$ is the tax rate on dividends, $T_{d t}$ is the number of days to payment of dividend taxes. The cash flows are known and therefore discounted by the risk free rate of interest. $D^{d t l}$ is therefore the present value of the tax on dividends.

\section{Capital gains tax}

The capital gains tax from a sale of the stock at time ts is:

$$
\tau_{c}\left[E\left(P_{t_{s}}\right)-P_{t_{0}}\right]=\tau_{c} E\left(P_{t_{s}}\right)-\tau_{c} P_{t_{0}}
$$

The sale of shares occurs after $T_{s}$ days (at time $t_{s}$ ). For active traders it is assumed that the stock is sold on the ex-day, that is $T_{s}=1$ whereas for passive traders $T_{s}>1$. Capital gains tax on this transaction is due after $T_{c}$ days where $T_{c}>T_{s}$, and capital gains taxes may not be due until nearly two years after the sale of the stock. The present value of the second term is straightforward, the amount is known at time zero and the discount rate is therefore the risk free rate of interest. From the time of purchase to the time of sale, the present value of the first term is a stochastic variable and it therefore has to be discounted for the first $T_{s}$ days by the risk adjusted rate. After the sale of the stock until the payment of taxes, the value is known and the risk free rate is therefore used for the period $T_{c}-T_{s}$. The present value of the capital gains tax at time zero is therefore:

$$
\tau_{c} C G=\tau_{c}\left[E\left(P_{t_{s}}\right) e^{-T_{s} r-r_{f}\left(T_{c}-T_{s}\right)}-P_{t_{0}} e^{-r_{f} T_{c}}\right]
$$

where $r$ is the risk adjusted rate.

\section{Sales Price}

Finally, the expected sales price, $P_{t s}$, is discounted back $T_{s}$ days to time zero using the risk adjusted rate, $r$ : 


$$
E(P)=E\left(P_{t_{s}}\right) e^{-r T_{s}}
$$

\section{Expected Payoff from Investment Strategies}

The expected payoff at the cum-day, $t_{0}$, from buying and holding the stock for $s$ days is therefore given by:

$$
E\left(\pi_{t_{0}}\right)=-P_{t_{0}}-\tau_{c} C G+D^{N T}+D^{T}-\tau_{d} D^{d t l}+E(P)
$$

where $t_{0}$ is the cum-dividend date. This expression is analyzed below for the three different kinds of marginal investors.

\section{A. Passive or Long Term Investor}

The passive trader can buy the stock on the cum-day or on the ex-day and sell it after $s$ days. Recall that a passive trader does not pay capital gains tax and the expected payoff from buying on the cum-day is:

$$
E\left(\pi_{t_{0}}\right)=D^{T}+D^{N T}-\tau_{d} D^{d t l}+E(P)-P_{t_{0}} .
$$

If a passive trader buys a stock on the ex-day, $t_{1}$, and holds it for " $s-1$ " days, the expected payoff at time zero from this transaction is:

$$
E\left(\pi_{t_{0}}\right)=-E\left(P_{t_{1}}\right) e^{-r}+E(P) .
$$

For the markets to be in equilibrium, these two strategies must result in the same expected payoff. Therefore, the equilibrium condition for a passive trader is:

$$
P_{t_{0}}-E\left(P_{t_{1}}\right) e^{-r}=D^{T}+D^{N T}-\tau_{d} D^{d t l}
$$

which for stock $i$ can be rewritten as:

$$
\Delta P_{t_{0}, i}=D_{i}^{A D}-\tau_{d} D_{t}^{d t l},
$$

where:

$$
\begin{aligned}
& \Delta P_{t_{0}, i}=P_{t_{0}, i}-E\left(P_{t_{1}, i}\right) e^{-r} \text { and } \\
& D_{i}^{A D}=D_{i}^{T}+D_{i}^{N T} .
\end{aligned}
$$


If discounting of various cash flows is ignored, (i.e. setting $T_{p}=T_{d}=0$ ) then (4) yields (for the case of no-tax free dividends):

$$
\Delta P_{t_{0}, i}=D_{i}^{T}\left(1-\tau_{d}\right) \Rightarrow\left\langle\frac{\Delta P_{t_{0}}}{D_{i}^{T}}\right\rangle=\left(1-\tau_{d}\right) .
$$

Expression (6) has been used in prior studies to test for tax effects in ex-dividend pricing. However, (5) differs from (6) in the following ways. In (5) the cash flows are discounted back to the present whereas in (6) it is assumed that taxes and dividends are paid on the ex-day. The time difference between ex-day and the payment of dividends is approximately 16 days on average and it is usually of little importance whether the delay between ex-day and actual payment of the dividends is accounted for. The dividend tax liability, however, may not be due for up to two years so the net present value may be significantly different to the actual amount of tax. In particular this is the case in periods with high interest rates. $D^{d t l}$ is different to $D^{T}$ so it is not possible to use a straight inverted, divided yield or drop ratio, $\left(P_{t_{0}}-P_{t_{1}}\right) / D^{T}$, to test for passive or long term traders in ex-dividend pricing. The correct measure is an adjusted drop ratio: $\left(P_{t_{0}}-P_{t_{1}}\right) / D^{d t l}$. Since $D^{d t l}<D^{T}$ the standard drop measure given in (6) yields a downward biased estimate of $\tau_{d}$. For the case of two types of dividends it is advantageous to work with the following expression for empirical tests:

$$
\Delta P_{t_{0}, i}=\gamma_{0} D_{i}^{A D}-\gamma_{2} D_{i}^{d t l}+\varepsilon_{i, t}
$$

The test for a passive or long term investor is:

$$
\gamma_{0}=1 \text { and } \gamma_{2}=\tau_{d} \text {. }
$$

\section{B. Active or Short Term Trader}

As with passive traders there are two possible strategies for active traders; buy or sell at the cum-day or at the ex-day.

Buying the Share Cum-Dividends:

The payoff from this strategy is derived from (1) and is given by:

$$
E\left(\pi_{t_{0}}\right)=-P_{t_{0}}-\tau_{c} C G+D^{T}+D^{N T}-\tau_{d} D^{d t l}+E(P)
$$


Buying the Share on the Ex-Day

The expected value at the cum-day for this transaction, derived from (1), is:

$$
\begin{aligned}
E\left(\pi_{t_{0}}\right)= & -E\left(P_{t_{1}}\right) e^{-r}-\tau_{c}\left[E\left(P_{t_{s}}\right) e^{-\left(r T_{s}+r_{f}\left(T_{c}-T_{s}\right)\right)}\right. \\
& \left.-E\left(P_{t_{1}}\right) e^{-\left(r+r_{f}\left(T_{c}-1\right)\right)}\right]+E(P)
\end{aligned}
$$

The capital gains component for the sales price differs from (8) since the purchase price is not known until the ex-day but expectations are taken at time zero. Thus the expected purchase price is discounted back for one day using the risk adjusted rate. Using the following approximation

$$
-E\left(P_{t_{1}}\right) e^{-\left(r+r_{f}\left(T_{c}-1\right)\right)}+P_{t_{0}} e^{-T_{c} r_{f}} \approx\left[P_{t_{0}}-E\left(P_{t_{1}}\right) e^{r}\right] e^{-r_{f}\left(T_{c}-1\right)}
$$

and setting (8) equal to (9) and collecting term yields:

$$
P_{t_{0}}-E\left(P_{t_{1}}\right) e^{-r}=\frac{D^{T}+D^{N T}-\tau_{d} D^{t d l}}{1-\tau_{c} e^{-r_{f}\left(T_{c}-1\right)}}
$$

Using the same notation for stock " $i$ " as for the long term trader in (5), (11) can be rewritten as:

$$
\Delta P_{t_{0, i}}=\frac{1}{1-\tau_{c} e^{-r_{f}\left(T_{c}-1\right)}}\left(D_{i}^{A D}-\tau_{d} D_{i}^{d t l}\right)
$$

The empirical model used to test for an active trader is:

$$
\Delta P_{t_{0, i}}=\frac{1}{1-\gamma_{1} e^{-r_{f}\left(T_{c}-1\right)}}\left(D_{i}^{A D}-\gamma_{2} D_{i}^{d t l}\right)+\varepsilon_{i, t}
$$

and a general test for active traders is:

$$
\gamma_{1}=\tau_{c} \text { and } \gamma_{2}=\tau_{d}
$$


Notice that the exponential expression in the denominator of (13) is different for different stocks since the number of days until taxes are actually paid differs across stocks. As a result of this, (13) is non-linear in the parameters.

To explore the impact of using discounted dividends and tax payments, " $T_{p}$ ", " $T_{c}$ " and " $T_{d}$ " are set to zero in (12) for the case of taxable dividends only:

$$
\Delta P_{t_{0}, i}=\frac{\left(1-\tau_{d}\right)}{\left(1-\tau_{c}\right)} D_{i}^{T} \Leftrightarrow\left\langle\frac{\Delta P_{t_{0}}}{D^{T}}\right\rangle=\frac{\left(1-\tau_{d}\right)}{\left(1-\tau_{c}\right)}
$$

As for the case of passive or long term investors, (14) is equivalent to the expression used in the literature to test for active traders. A test for the existence of an active trader, who pays the same income tax rate on both dividends and capital gains, is a test of whether or not the drop ratio is equal to one. Equations (13) and (14) are significantly different. In particular, (13) is non-linear in the parameters whereas (14) is a simple linear t-test of the drop ratio. If there is a significant delay between the time of trade and payment of taxes, (14) (and (6)) is misspecified and cannot be used to test for active (passive) traders.

\section{Mixed Investor}

The last type of investor is a mixed investor who has the option of being taxed either as a long term investor or as a short term investor. Investors who maintain two sets of books and purchase shares on the cum-dividend day have the option of being taxed on the subsequent sale either as a passive or active trader. If they buy the share cum-dividend, they can then choose to be taxed as an active trader by selling the stock on the ex-dividend day or as a passive trader by selling the stock at a time in the future. While the U.S. specifies a long term trade based on the specific time period that the stock is held, the New Zealand tax code does not specify for how long a stock has to be held to be classified as a passive investment. Only the intent at the time of purchase matters. The implementation of such a law is obviously difficult, but one of the main arguments a trader can use to prove that a transaction should be entered into the active trading book is the length of time the stock is held. In this paper we, therefore, assume that the stock is sold after one day (the ex-day) if it is an active trade and held for $s$ days $(s>1)$ if it is 
a passive trade. Using only one day to maturity is likely to understate the value of the option and bias the results in favour of not finding any mixed investors in the sample.

\section{Mixed Investor Buying Cum-Dividends}

The payoff at $t_{1}$ to a mixed trader is therefore given by:

$$
\pi_{t_{1}}^{M}=\max \left(\pi_{t_{1}}^{P}, \pi_{t_{1}}^{A}\right)
$$

where $\pi_{t_{1}}^{P}$ is the payoff if the investor chooses to be taxed as a passive or long term trader and $\pi_{t_{1}}^{A}$ is the payoff from an active or short term strategy. The payoff at time $t_{1}$ to the passive or long trading strategy is derived from (2) by taking the expectations at time $t_{1}$ instead of at time $t_{0}$, adjusting the number of days to tax payments, and noticing that $P_{t_{0}}$ has already been paid and is therefore not part of the payoff at time $t_{1}$. The payoff at time $t_{1}$ for the active trading strategy can be obtained from (9) by making the same adjustments as for the passive trading strategy. The payoffs to the two types of trading strategies are:

$$
\begin{gathered}
E\left(\pi_{t_{1}}^{P}\right)=\left(D_{t_{p}}^{T}+D_{t_{p}}^{N T}\right) e^{-\left(T_{p}-1\right) r_{f}} \\
-\tau_{d} D_{t_{d t}}^{T} e^{-\left(T_{d t}-1\right) r_{f}}+E\left(P_{t_{s}}\right) e^{-r\left(T_{s}-1\right)}
\end{gathered}
$$

and

$$
\begin{gathered}
\pi_{t_{1}}^{A}=-\tau_{c}\left(P_{t_{1}}-P_{t_{0}}\right) e^{-\left(T_{c}-1\right) r_{f}}-\left(D_{t_{p}}^{T}+D_{t_{p}}^{N T}\right) e^{-\left(T_{p}-1\right) r_{f}} \\
-\tau_{d} D^{T} e^{-\left(T_{d}-1\right) r_{f}}+P_{t_{1}}
\end{gathered}
$$

The active trader sells the stock at time $t_{1}$ whereas the passive trader sells at time $t_{s}$. Thus the payoff to the active trader is known with certainty at time $t_{1}$ but the payoff to the passive or long term trading strategy is a random variable. The future price, however, is discounted back at the risk adjusted rate and the expected payoff to the long term or passive trading strategy can therefore be compared to the certain payoff from the active strategy. Substituting (16) and (17) into (15), collecting terms and adopting the convention from above that variables 
without time subscripts are present values yields the following payoff to the mixed investor at time $t_{1}$ :

$$
\begin{gathered}
E\left(\pi_{t 1}^{M}\right)=D^{T}+D^{N T}-\tau_{d} D^{d t l}+E(P) \\
-\max \left[0, P_{t_{1}}-E(P)-\tau_{c}\left(P_{t_{1}}-P_{t_{0}}\right) e^{-\left(T_{c}-1\right) r_{f}}\right]
\end{gathered}
$$

The payoff is the present value of after-tax dividends plus the present value of the expected future sales price plus an option. The first term in the option, $P_{t_{1}}-E(P)$, is the difference between the price at $t_{1}$ and the present value of the sales price. In an efficient market we would expect this term to be zero. However, if the trader has inside information, this term can be negative or positive. The second term in the option,

$$
-\tau_{c}\left(P_{t_{1}}-P_{t_{0}}\right) e^{-\left(T_{c}-1\right) r_{f}},
$$

s the capital gains tax payable if the stock is bought cum-dividend and sold ex-dividend. The tax is payable in $T-1$ days and is discounted at the risk free rate since it is know at time $t_{1}$. In general, the second term is expected to be negative since the share price drops when the stock goes ex-dividend. The second term induces the trader to behave as a short term trader because doing so adds positive value to the overall trade. If, however, there are gains from insider information then the trader will hold on to the stock, i.e., behave as a long term trader.

The stochastic variable driving the option value is the share price and the exercise price is $P_{t_{0}}$. We can further write the expected payoff to the mixed trader as:

$$
\begin{gathered}
E\left(\pi_{t_{1}}^{M}\right)=D^{T}+D^{N T}-\tau_{d} D^{d t l}+E(P) \\
+\tau_{c} e^{-\left(T_{c}-1\right) r_{f}} \max \left[0, \varpi+P_{t_{0}}-P_{t_{1}}\right],
\end{gathered}
$$

where

$$
\varpi=\frac{1}{\tau_{c} e^{-\left(T_{c}-1\right) r_{f}}}\left(P_{t_{1}}-E(P)\right)
$$

represents the gains from insider information.

The expected value of the payoff at time $t_{0}$, the cum-day, is given by: 


$$
\begin{gathered}
E\left(\pi_{t_{0}}^{M}\right)=-P_{t_{0}}+D^{T}+D^{N T}-\tau_{d} D^{d t l}+E(P) \\
+\tau_{c} e^{-\left(T_{c}-1\right) r_{f}} C\left(r_{f}, \sigma, \omega, \gamma, P_{t_{0}}, P_{t_{1}}\right)
\end{gathered}
$$

here $C(\cdot)$ represents the option value, $s$ is the standard deviation of the stock returns, $\gamma$ is the jump parameter due to the stock going ex-dividend, (which in this case is equivalent to the drop in share price between the cum and ex-day), $\omega$ is the expected return to insider information. The maturity of the option is very short, and is the same for all the stocks, and $r_{f}$ is the risk free rate of interest. An increase in the volatility will increase the value of the option, an increase in the drop ratio will decrease both the value of $P_{t_{1}}$ and $E(P)$, leaving the first term unaffected. An increase in the dividend yield, however, increases the capital loss from the decrease in the price and so increases the tax deduction to the active trader and the value of the option. An increase in the return from insider information will decrease the value of the option because being a passive, long term, investor is more valuable. Finally, an increase in $T$, the number of days to the payment of tax, decreases the value of the option by reducing the tax benefit, by reducing the present value of the tax-deduction from being an active investor.

The mixed investor also has the opportunity of buying the stock on the ex-day and being taxed as a long term investor. The expected payoff as of the cum-dividend day, $t_{0}$, is given by:

$$
E\left(\pi_{t_{0}}\right)=-E\left(P_{t_{1}}\right) e^{-r}+E\left(P_{t_{s}}\right) e^{-r T_{s}}
$$

For the markets to be in equilibrium, the expected payoffs given by (19) and (20) must be the same. Therefore, the equilibrium condition for the mixed trader is:

$$
\begin{gathered}
-P_{t_{0}}+D^{T}+D^{N T}-\tau_{d} D^{d t l}+E(P) \\
+\tau_{c} e^{-\left(T_{c}-1\right) r_{f}} C\left(r_{f}, \sigma, \omega, \gamma, P_{t_{0}}, P_{t_{1}}\right)=-E\left(P_{t_{1}}\right) e^{-r}+E(P) \Leftrightarrow \\
P_{t_{0}}-E\left(P_{t_{1}}\right) e^{-r}=D^{T}+D^{N T}-\tau_{d} D^{d t l} \\
+\tau_{c} e^{-\left(T_{c}-1\right) r_{f}} C\left(r_{f}, \sigma, \omega, \gamma, P_{t_{0}}, P_{t_{1}}\right)
\end{gathered}
$$


As for the other cases this expression has an empirical counterpart which can be written as:

$$
\Delta P_{t_{0}, i}=D_{i}^{A D}-\gamma_{2} D_{i}^{d t l}+\beta_{1} \text { adOption }_{i, t}+\varepsilon_{i, t}
$$

where

$$
\text { adOption }_{i, t}=e^{-\left(T_{c}-1\right) r_{f}} C\left(r_{f}, \sigma, \gamma, P_{t_{0}}, P_{t_{1}}\right)
$$

is the adjusted value of the option. The left hand side represents the expected drop in price and the right hand side is the net present value of the dividends. Compared to previous studies, (20) explicitly takes into account that taxes are not payable immediately. The model also explicitly integrates the option generated by the specific tax laws in New Zealand. Similar options would be available in other tax regimes where specific criteria determine the tax status of gains from stock trades.

The three equilibrium conditions represented by the equations (7), (13) and (22) are nested into an empirical model that can be tested. The empirical model is given by:

$$
\begin{aligned}
\Delta P_{t_{0}, i}=\alpha & +\frac{1}{1-\gamma_{1} e^{-\left(T_{c i t}-1\right) r_{f}}}\left(D_{i, t}^{A D}-\gamma_{2} D_{i, t}^{d l l}\right) \\
& +\beta_{1} \text { adOption }_{i, t}+\varepsilon_{i, t} .
\end{aligned}
$$

An intercept term was added to capture any constant effects.

The predicted values of the parameters in the nested empirical model (23) for the different traders are equivalent to the individual models given by (7), (13) and (23). These are summarized in table 1 . Notice that active traders in New Zealand face the same income tax rate on dividends and capital gains.

In summary, in this section it was argued that in New Zealand three different types of investors may dominate different stocks around the ex-day. The active and passive investors are equivalent to the ones tested for in the U.S. and other countries. A third type of investor is also identified here, namely, a mixed investor who has the option of being taxed as either an active of passive investor. ${ }^{6}$ Finally, the fact that taxes

6. The model is also relevant for other countries. For example, the U.S. allows an investor to be taxed as a short term investor if the stock is sold within, e.g., 6 months 
TABLE 1. Parameter Predictions

\begin{tabular}{llll}
\hline & $\gamma_{1}$ & $\gamma_{2}$ & $\beta_{1}$ \\
\cline { 2 - 4 } & 0 & $-\tau$ & 0 \\
Passive trader & 0 & $-\tau$ & + \\
Mixed trader & $\tau$ & $-\tau$ & 0 \\
Active trader & $\tau$ & & 0 \\
\hline
\end{tabular}

Note: The predictions for the three type of traders are based on the model

$$
\Delta P_{t_{0, i}}=\frac{1}{1-\gamma_{1} e^{-r_{f}\left(T_{c t i}-1\right)}}\left(D_{i}^{A D}-\gamma_{2} D_{i}^{T N}\right)+\varepsilon_{i, t} .
$$

$\Delta P_{t_{0}}=P_{t_{0}}-E\left(P_{t_{1}}\right) e^{-r}$, where $r$ is the risk adjusted discount rate, $T_{C i t}$ he number of days to the payment of tax, $r_{f}$ is the risk free rate of return. $D_{i, t}^{A D}$ and $D_{i, t}^{T N}$ are the present values of dividends paid at the ex-day and payable in $T$ days, respectively. AdOption is the value of the $\operatorname{tax}$ tax option of switching between being a active and passive investor. $\tau$ is the marginal income tax rate.

incurred as a consequence of trading around the ex-day may not be payable for nearly two years is explicitly taken into account. If incremental taxes, as a consequence of trading around the ex-day, are not due for a while after the actual trade then, as shown above, the models used in the literature to test the various ex-day pricing theories are misspecified.

Before providing the results obtained from testing (23), the data used is discussed in the next section.

\section{Data}

The data consists of daily price quotations of listed companies on the New Zealand Stock Exchange between 1 January 1982 and 31 July 1985 and the dividends on those shares for the same periods. All data entries have been individually checked. The database also includes adjustment factors for capital changes and splits and price lags, i.e., the age of the price or when the stock was last traded. The database is compiled and maintained by the Department of Finance and Quantitative Analysis at the University of Otago.

To be included in the study, shares had to satisfy the following requirements:

(depending on the time period). 
TABLE 2. Sample Composition

\begin{tabular}{lcccc}
\hline & $\begin{array}{l}\text { Only } \\
\text { taxable } \\
\text { dividends }\end{array}$ & $\begin{array}{l}\text { Only non- } \\
\text { taxable } \\
\text { dividends }\end{array}$ & $\begin{array}{l}\text { Taxable and } \\
\text { non-taxable } \\
\text { dividends }\end{array}$ & Total \\
\cline { 2 - 5 } & 150 & 256 & 63 & 469 \\
$\begin{array}{l}\text { Number of dividend events } \\
\text { where the firm paid ... }\end{array}$ & 37 & 52 & $62 *$ & 153 \\
Number of companies that paid $\ldots$ & 37 &
\end{tabular}

Note: $* 38$ different companies paid both types of dividends on the same day.

Be listed in a window of -40 to +40 around the ex-day.

Be traded on the cum and ex-day.

Have at least 6 prices in total in the window -40 to -5 and +5 to +40 to facilitate return calculations.

A total of 469 observations fit these criteria and form the basic sample. As is evident from table 2, the number of dividend events with only one type of dividend payment on the same day is 406, comprising 150 taxable dividends and 256 non-table dividends. In a further 63 cases, both types of dividends were paid on the same day. A total of 153 different companies generated the 469 dividend events, 37 companies paid only taxable dividends and 52 companies paid only non-taxable dividends over the period. A total of 62 companies paid both types of dividends in the period of which 38 different companies paid two dividends on the same day. Thus, the different types of dividends are relatively evenly spread over different companies.

Figure 2 shows a histogram of the percentage drop in prices between the ex and cum-day. Clearly, there are too many cases indicating no drop to be believable. This situation may have been caused by:

Wrong ex-day. The sources were double checked. It is possible that some of the dates reported are not correct but the weekly diaries from the stock exchange were used and these should be accurate.

There was no trade on the ex-day, making the cum-price equal to the ex-price. Again, data entries were checked against the newspapers and, in general, showed a trade on the relevant days.

The volume indicated in the papers on these days was rather small. This may be a result of either a special trade where dividends are 


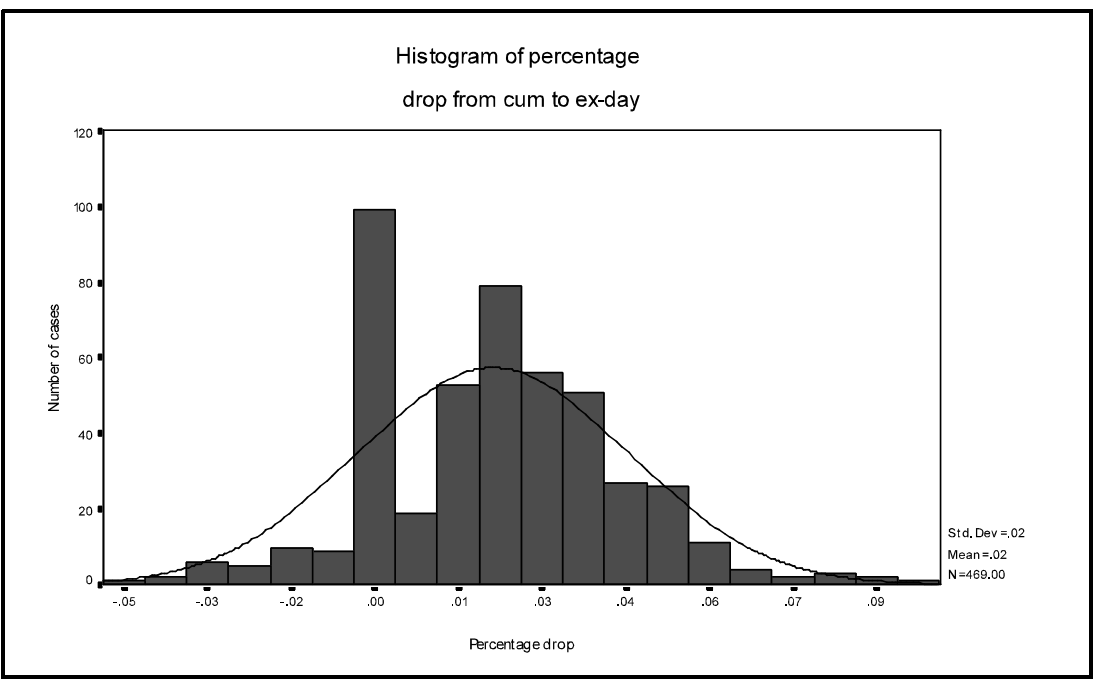

FIGURE 2.-Price Drop Between Cum- and Ex-day

included on the ex-day or overhanging limit orders, that is, limit orders that have not being adjusted for dividends or cancelled.

Furthermore, these "outliers" were analyzed with respect to dividend yield and thin trading. If these stocks all had low dividend yield, transactions costs may prohibit trading around the ex-day to exploit profit possibilities. As can be seen from table 3, there is no apparent difference in dividend yield between the stocks with price changes from the cum-day to the ex-day and the ones for which the price did not change. Both samples have an annual dividend yield of about $6 \%$ or $3 \%$ per dividend payment (semi-annual payments). Nor does the thin trading measure show any significant difference. In summary, it is not apparent why prices did not change on these stocks, and it is not clear how these observations should be treated. The analysis below is, therefore, undertaken with and without these stocks.

In an effort to overcome data problems and to exploit the unique feature of the data set, where in the same firm could pay both taxable and non-taxable dividends on the same day, the analysis was performed on three data sets. The first data-set contains all 469 observations. In the second data set the observations with no change in the price around the ex-day were dropped leaving a total of 370 observations. Finally, the 
TABLE 3. Analysis of "Outliers"

\begin{tabular}{lcc}
\hline & Stock where $P_{t-1}=P_{t}$ & Stock where $P_{t-1} \neq P_{t}$ \\
\cline { 2 - 3 } Dividend yield & 0.0285 & 0.0307 \\
Thin trading & 0.8507 & 0.8694 \\
Number of obs. & 98 & 371 \\
\hline
\end{tabular}

Note: From figure 1 there may be an abnormal number of stocks where the price did not change between the ex- and cum-days. The dividend yield is the total dividends (taxable plus non-taxable) paid divided by the cum-price. The thin trading measure is the number of days measured in percentage, the stock traded in the window -40 to +40 , excluding five days around the dividend..

third set contains only stocks with a taxable and a non-taxable dividend on the same day; with 63 observations.

Table 4 contains the descriptive statistics for the different drop measures, $\Delta P_{t_{0}, i}$,scaled by the total dividends. If passive traders are the dominant traders, the drop measure should be below one for taxable dividends and one for non-taxable dividends. Consistent with a passive trader, the drop ratio is significantly larger for non-taxable dividends; the T-test for differences in means between the taxable and non-taxable dividends are significant for all three measures. However, the coefficient for the non-taxable dividends is significantly smaller than one for all measures. If active traders were the dominant traders, the drop measure should equal one for taxable dividends and be larger than one for non-taxable dividends. This is clearly not the case. The data is consistent with the existence of passive traders and a general tax effect.

\section{A. Dependent Variable}

The dependent variable in the empirical model (23) is calculated in two different ways:

$$
\text { mean adjusted }=P_{t_{0}}-E\left(P_{t_{1}}\right) e^{-\bar{r}} \text {. }
$$

In this measure, the difference between the cum and ex-dividend price is discounted by the average daily return of the stock in window -40 to plus 40 days around the ex-day excluding plus/minus five days around the ex-day. The second measure is: 


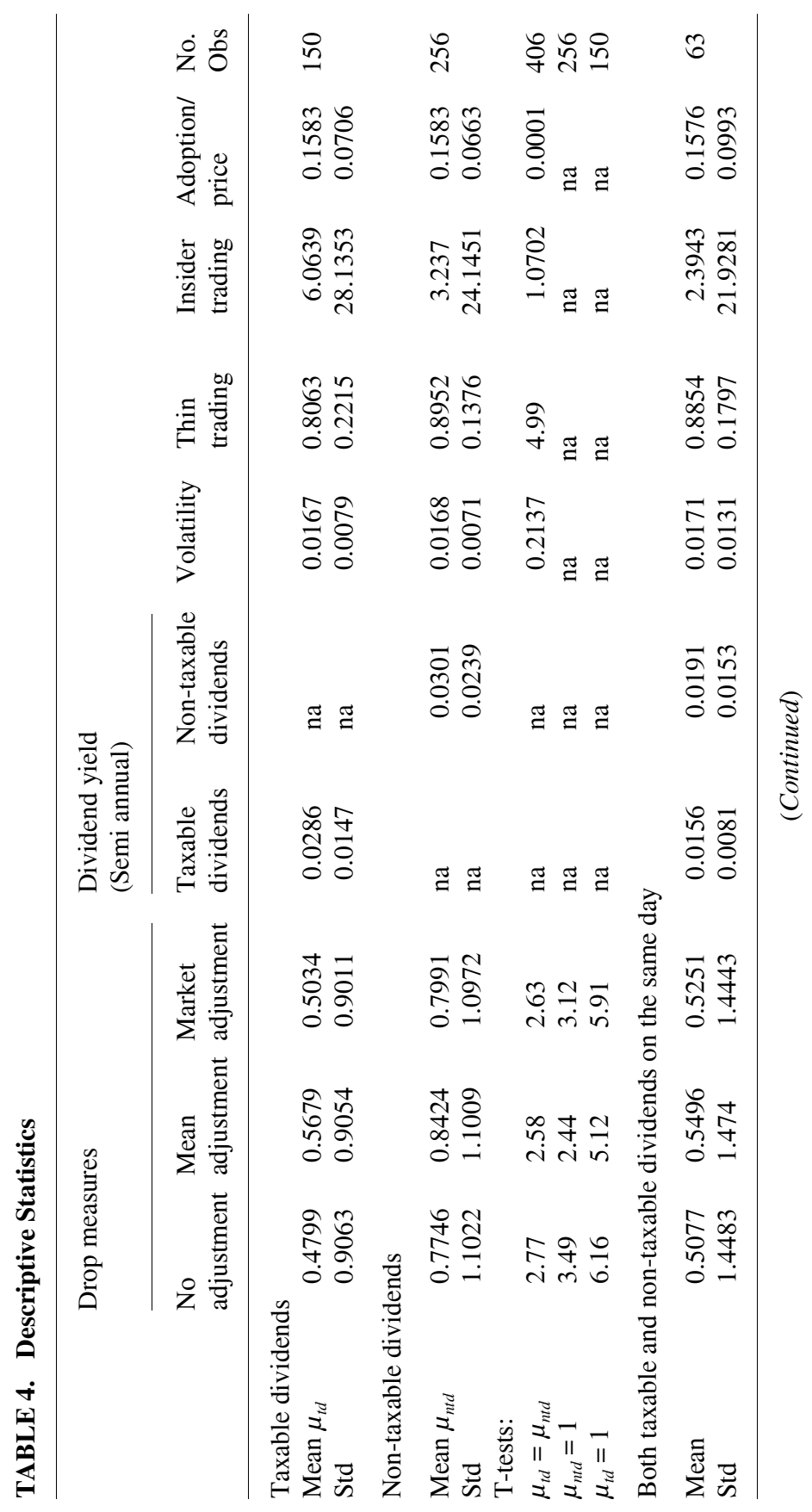




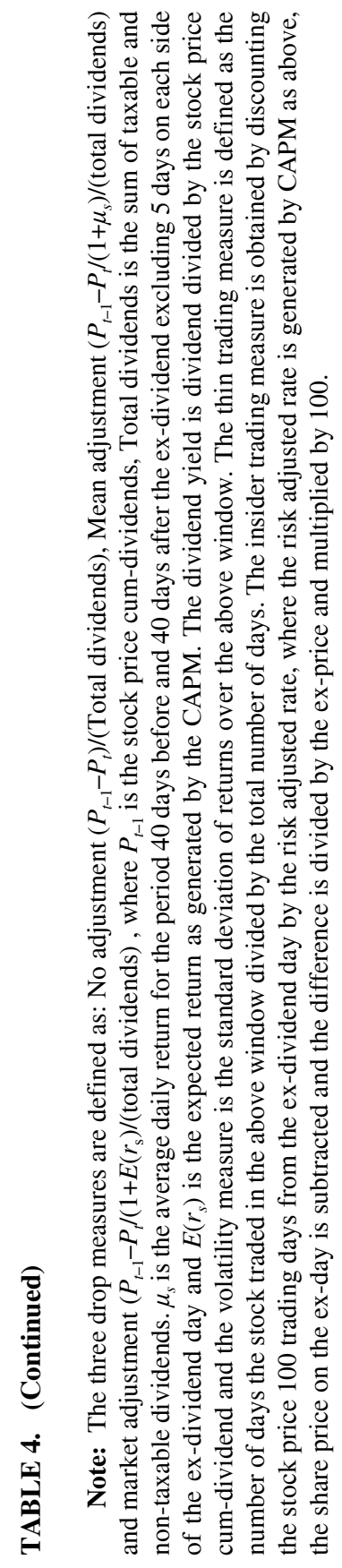




$$
\text { market adjusted }=P_{t_{0}}-E\left(P_{t_{1}}\right) e^{-\left(r_{f}+0.06 \beta\right)}
$$

This measure is a risk adjusted measure. The beta is calculated as a trade-by-trade beta to account for thin trading during the window -40 to +40 excluding the 11 days around the ex-day. ${ }^{7}$ The risk free rate is the 90 bank bill rate and the excess return on the market is set to $6 \%$; see Chay et al. (1996).

\section{B. Valuing the Option}

For the right hand side of (21), the value of the option was also calculated in two ways. The value of the option at time $t_{0}$ is:

$$
C=\tau_{c} e^{-\left(T_{c}-1\right) r_{f}} C\left(\sigma, \gamma, \omega, r_{f}\left(P_{t_{0}}-P_{t_{1}}\right)\right)
$$

For the purpose of pricing the option it is assumed that insider information is nonexistent or small enough to have no effect on the marginal price. This assumption is likely to bias downwards the value of the option and, therefore, also bias downwards the likelihood of finding a mixed marginal investor. The standard deviation was calculated using daily returns for 35 days prior to the ex-day window where the window is defined as plus-minus 5 days around the ex-day. The time to maturity was set to one day. Again the risk free rate was the 90 day bank bill rate.

In the first model, the jump parameter was ignored, and the Black and Scholes model was used to evaluate the option. The European formula was used because the valuation was being made on the cum-day and the option was being sold on the ex-day. The option is at the money, so the strike price is the current share price in this model.

Adjusting for the jump parameter which is a feature of the true option is nontrivial. The problem is clearly that the jump parameter or drop is equal to, or a function of, the drop ratio which is the variable on the left hand side of the regression equation (23). Given the difficulties arising from the non-linear nature of this problem, the second method for calculating the value of the option uses the current price adjusted for total dividends. The values from the two models were regressed against

7. See Bartholdy and Riding (1994) for a discussion of these issues for New Zealand data. 
each other, and the results indicated almost perfect correlation between the two $\left(R^{2}=0.99\right)$. For further empirical work, the average of the two estimates was used as the value of the option. As can be seen from table 4 , the average value of the option as a percentage of the price of the stock is around $15 \%$ for all three types of dividend payments.

\section{Summary}

The standard procedure in the literature is to test the predictions of the various equilibrium conditions and from these infer the dominant marginal investor. In these tests it is implicitly assumed that the same investor type dominates the equilibrium for all stocks. In a world with short sales and many investors this may be feasible. But in New Zealand short sales were prohibited during the testing period. The ability to exploit profit opportunities on the sales side was limited by the number of shares the investors held in their portfolios. Since the profits from the various strategies are all stochastic, risk averse investors would be reluctant to purchase unlimited amounts of a single stock and thereby give up diversification. The implication of these restrictions is that one type of investor may not be able to dominate all stocks at all times; different types of investors may dominate different stocks. This type of equilibrium is referred to as a separating equilibrium. The model here is therefore estimated under the assumption of both a dominating and a separating equilibrium.

\section{Dominating Equilibrium}

The results of estimating (23), under the assumptions that one type of investor dominates all trades, are presented in table 5. As indicated in the discussion of table 1 , if (23) is valid then $\gamma_{2}$ is significant and the same is the case for all traders as this represents the tax liability on dividends. From table $5, \gamma_{2}$ is only significant when the outliers $\left(P_{t_{0}}-P_{t_{1}}=0\right)$ are dropped; not when all the observations or those with two dividends are used. When $\gamma_{2}$ is significant the value is, as predicted by the model, close to the marginal tax rate. From table 1 the predictions for a passive investor are that $\gamma_{2}$ is the only significant parameter. For a mixed investor to be dominating, both $\gamma_{2}$ and $\beta_{1}$ must be significant and for the active traders to dominate, both $\gamma_{1}$ and $\gamma_{2}$ must be significant. 


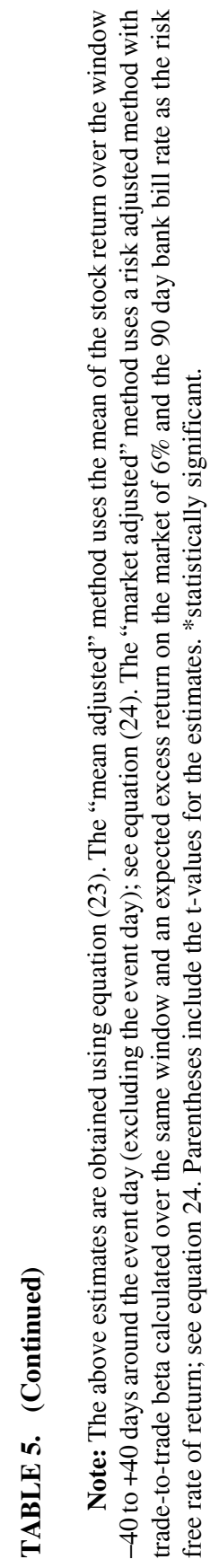


In general, table 5 provides no evidence of strictly active traders; $\gamma_{1}$ is never significant. The results also provide only weak evidence of mixed traders in the significance of $\beta_{1}$ for the market adjusted drop measure. This parameter indicates the value of the option to those investors who can choose their tax status. In this case, the significant values are dependent on the choice of measurement of the price drop. There is evidence of either a dominating equilibrium of mixed traders or a separating equilibrium of mixed and passive traders.

The problem with the results in table 5 is that if a separating equilibrium exists, the estimates are inefficient and biased. If different investors dominate different stocks, the results in table 5 represent the average over the three different types of investors. Given that $\gamma_{1}$, for example, is zero for passive traders and equal to the income tax rate for active traders, the results in table 5 would probably lie somewhere in between depending on the relative number of stocks dominated by each group of investors. As a consequence, the variance of the estimate would increase making the parameter insignificant. Since the parameters are different for different groups of stocks, they are no longer constant and the estimates in table 5 may, therefore, be biased as well. Considering the weak results obtained for a dominating equilibrium, a separating equilibrium is considered next.

\section{Separating Equilibrium}

The New Zealand institutional environment adds a constraint on short selling that limits the activities of investors relative to other regimes. Selling can only occur when shares are already held and buying is limited by the available liquidity of the investor. Investors are, therefore, constrained to trade in shares which they believe will be increasing in value. This is in contrast to the complete market situation where short selling provides liquidity and allows a different set of decisions relating to expected price drops. If tax effects are different as outlined above, and if investors trade with those differences in mind, then different classes of investors will gravitate toward shares that maximize their comparative advantage within the constraints described. The result could be that different types of stocks attract different types of marginal investors consistently enough to generate a separating equilibrium.

From the model derived above the following characteristics of stocks that may add value to the various classes of traders are suggested. 
Mixed traders, who have the option of choosing their tax status with every trade, should prefer high volatility stocks because the volatility will increase the value of the option. They should also prefer shares with little insider information, or stable expected growth, since the presence of either of these factors will reduce the value of the option. They should also prefer 'fat' traded stocks with high liquidity to maintain the value of the option and to be able to sell easily if the active position is chosen. Active traders should also prefer highly liquid stocks to maximize their ability to trade without barriers. These investors should also prefer stocks with high dividend yields since the drop in price provides a tax shield not available to long term investors. Passive investors should value low dividend yield shares for the opposite reason. They should also value the potential for insider information regarding high future growth.

The above discussion, derivation of the equilibrium model for the New Zealand situation, and prior analysis by Boyd and Jagannathan (1994) suggest four variables which might separate the observed trading activity into three groups of traders: volatility, thin trading (liquidity), insider trading gains, and dividend yield. These four variables are defined in the following way:

Volatility: the standard deviation of the return on the stock in the window of plus/minus 40 days around the ex-dividend day excluding the five days around the ex-dividend day.

Thin trading measures: even when the shares of a company trade on both the cum and ex-dividend days, thin trading might be a problem in pricing if there were, for example, only two trades on the relevant dates. To quantify the possible impact of this type of thin trading in the sample, a thin trading measure was defined by dividing the number trades by the number of days in the same window as for the volatility measure.

Insider gain measure: this was obtained by discounting back the stock price 100 trading days from the ex-day at the risk-adjusted rate, using the beta and market premium as calculated above. The difference between the actual price and the discounted price was used as a measure of insider gain or mispricing.

Dividend yield: The standard measure of dividend divided by price.

The values of these four variables for the different types of dividends are presented in table 4 . There does not appear to be any correlation 
between thin trading and volatility and tax status. Taxable dividends seem to have a smaller dividend yield compared to the non-taxable dividends. That is, firms appear to pay out a higher dividend if they are not taxed compared to the situations where they are. The insider trading measure seems to be higher for the taxable dividends than the other dividends. There is no obvious reason for this and it may be a function of the rather weak or dubious definition of this variable.

The empirical tests for a separating equilibrium involve two steps. In the first step each stock has to be assigned to a potential marginal investor based on the above four variables. In the second step (23) is estimated for each group of stocks in an attempt to test for the existence of different marginal investors.

\section{A. Separation of stocks into groups}

The main problem is how to separate the stocks into groups with respect to the above variables. An initial attempt of straight sorting based on the various variables was undertaken to no avail. It was therefore decided to use cluster analysis to divide the observations into groups.

The basic idea in cluster analysis is to group the stocks in such a way that stocks with similar characteristics regarding the above four variables are assigned to the same group or cluster. ${ }^{8}$ While the specified variables were postulated to influence investor behavior, the strength of influence and the possible interaction of the factors were unknown. Cluster analysis was, therefore, treated more or less as a black box to group the stocks. Then regression analysis in the form of a modified version of (23) was used to test the parameter restrictions for the different types of marginal investors.

The number of clusters and the assignment of observations to clusters are dependent on the method used for the cluster analysis. The SAS cluster analysis procedure provides several hierarchical methods based on varying distance algorithms. Because the presence of outliers or variables with large variances in the data can have a disproportionate influence on the clustering, the measures for the variables (volatility, insider trading, thin trading and dividend yields) were standardised to have a mean of zero and variance of one. In the first stage, all four variables were used with the following methods: Average, Centroid, Complete, Flexible, McQuitty, Median, Single and Ward..$^{9}$ The second

8. For a discussion of Cluster analysis see ch. 11 in Johnson and Dean (1982).

9. See SAS/STAT User's Guide, p. 519. 
stage involved using the same methods with from two to four of the separating variables since it is not clear whether all of the variables are important and how they interact.

For the large data set most of the methods yielded one cluster with $400+$ observations out of the 469 available and two clusters with very few stocks; equivalent to a dominating equilibrium that was rejected above. The "Flexible" and "Ward" options yielded a bit more spread and clusters produced by these procedures were, therefore, used below in the regression analysis. Separate analysis was done on the smaller data set with both types of dividends paid on the same day. In that case, the "complete" method produced a two cluster separation that was used for further analysis.

From table 6, using insider trading and volatility as separating variables, the Flexible procedure identified two clusters. Cluster one had a lower average thin trading and volatility measure than cluster two. This suggests that cluster one represents passive or long term traders as they do not benefit from higher liquidity or higher option values from higher volatility. The insider trading measure is positive for cluster one and negative for cluster two supporting the notion that cluster one represents long term or passive investors whereas cluster two represents mixed or active traders. The dividend yield is essentially the same in both clusters.

The Ward option produced three clusters, with thin trading and volatility as the separating variables. Cluster one is consistent with active or mixed traders based on the highest thin trading and volatility measure, but low dividend yield compared to the other clusters suggests passive or long term traders. Cluster two has the lowest thin trading and volatility measure, suggesting passive or long term traders, but the insider trading measure is the lowest and the dividend yield highest in this cluster, suggesting active or mixed traders. Cluster three has the highest insider trading measure, but the others fall in the middle of the three groups, providing no further support. Thus, the results are somewhat ambiguous for the Ward option.

For the shares which paid both taxable and non-taxable dividends on the same day, the Complete option produced two clusters based on insider trading and volatility. The results are ambiguous, with cluster one suggesting passive traders based on thin trading and volatility, but the insider trading measure suggesting active or mixed traders. The dividend yields are essentially the same for both clusters.

Below the various clusters are used to test for the existence of a 


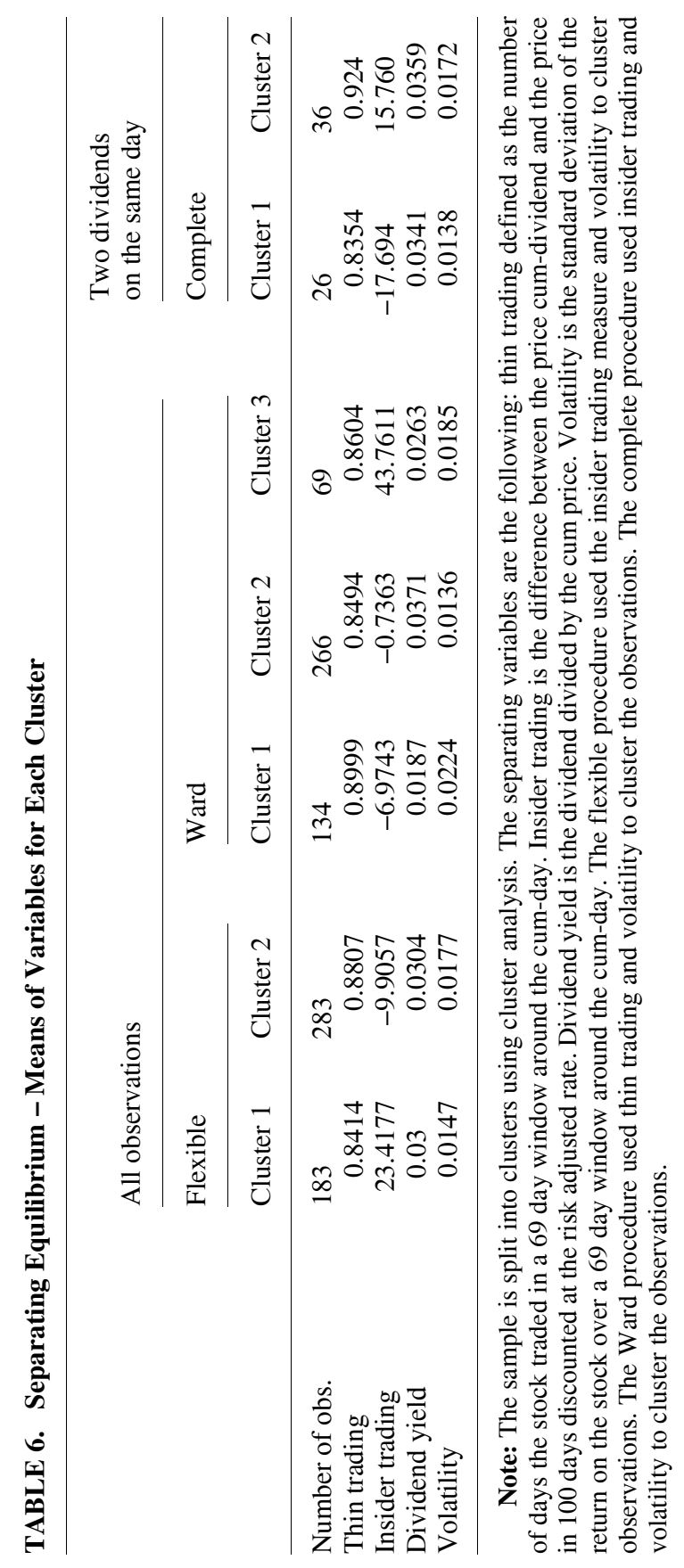


separating equilibrium. For a separating equilibrium the parameter estimates from (23) should be significantly different from the clusters identified by the Cluster analysis. This is the topic for the next section.

\section{B. Regression Analysis - Tests for a Separating Equilibrium}

While the cluster analysis showed that the observations could be classified by sorting based on the specified variables in at least three different ways, the results are only suggestive. To analyze each of the clusters further, the following revised version of (23) was used:

$$
\begin{gathered}
\Delta P_{t_{0}}=a_{1} Z_{1, t}+a_{2} Z_{2, t}+a_{3} Z_{3, t} \\
+\frac{1}{1-\left(\gamma_{1,1} Z_{1, t}+\gamma_{1,2} Z_{2, t}+\gamma_{1,3} Z_{3, t}\right) e^{-\left(T_{c i t}-1\right) r_{f}}}\left(D_{i, t}^{A D}+\gamma_{2} D_{i, t}^{T N}\right) \\
+\beta_{1,1} Z_{1, t} \text { adOption }_{i, t}+\beta_{1,2} Z_{2, t} \text { adOption }_{i, t}+\beta_{1,3} Z_{3, t} \text { adOption }_{i, t}+\varepsilon_{i, t}
\end{gathered}
$$

where $Z_{i, t}=1$ for $i=1,2$ and 3 if the observations belong to cluster $i$ and zero otherwise. Notice that there is no dummy variable on the dividend tax term since all the investors face the same dividend tax rate. The Flexible and Complete options only require two cluster dummies. If a separating equilibrium exists, and the above cluster analysis is able to identify the various groups of stocks associated with each marginal investor, then (26) should provide different estimates for the parameters across the different clusters each representing a marginal investor.

The results from estimating (26) for the larger data set are presented in table 7. The results for the smaller set with both taxable and non-taxable dividends paid on the same day are discussed below. As table 7 indicates, $\gamma_{2}$ is significant in all runs regardless of clustering methods, and the value is around $40 \%$. Based on the actual rates for the period, this is a reasonable figure for the average marginal tax rate on dividends. This result alone indicates an improved model compared to the dominating equilibrium result and suggests that there is indeed a taxation effect present in ex-dividend pricing. Furthermore, as is evident from table $7, \gamma_{1, i}$ is insignificant regardless of clustering method and drop measure used which suggests that strictly active traders were not present in the market.

From the Flexible clustering option in table 7, there is evidence of 


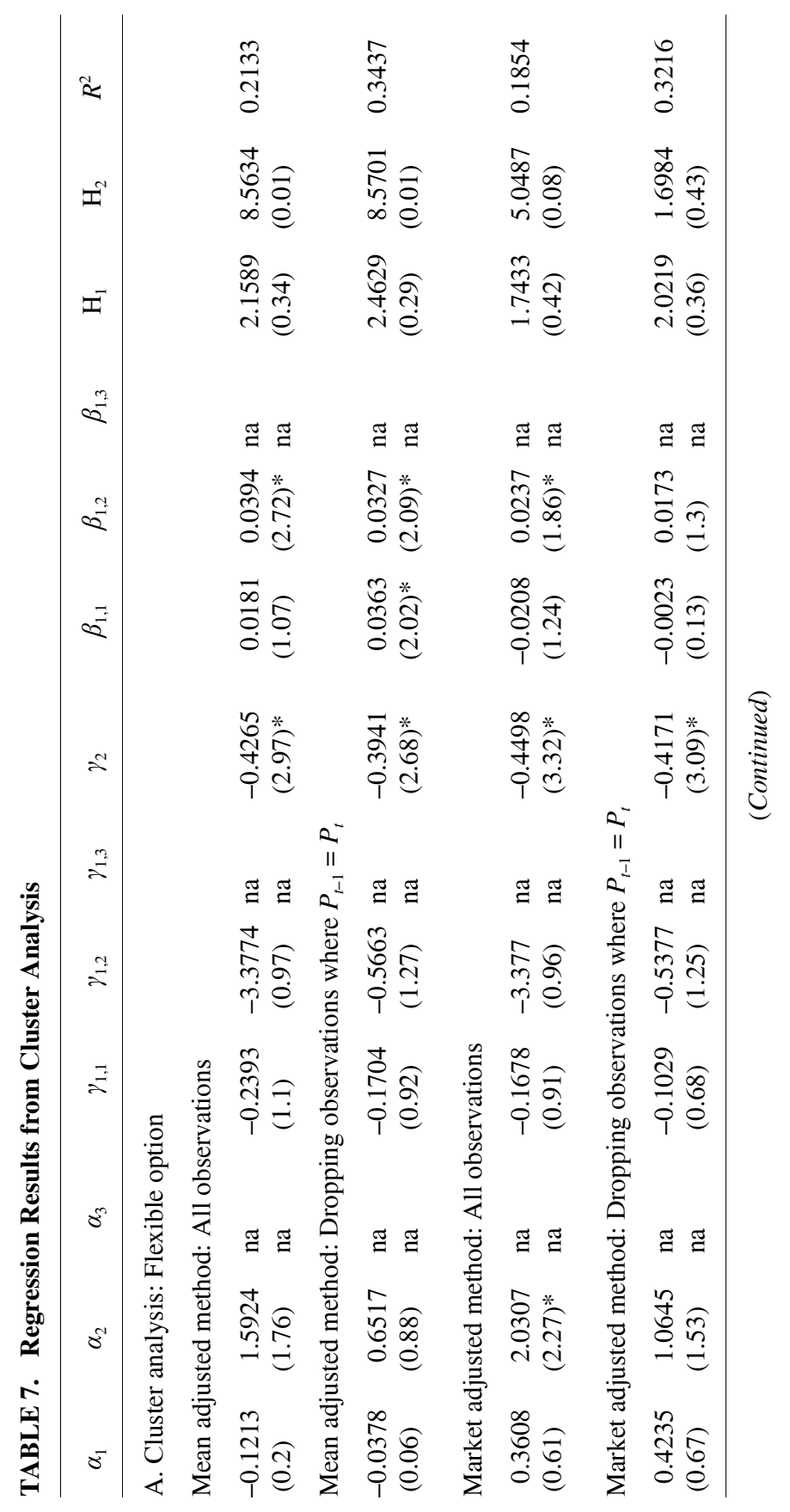




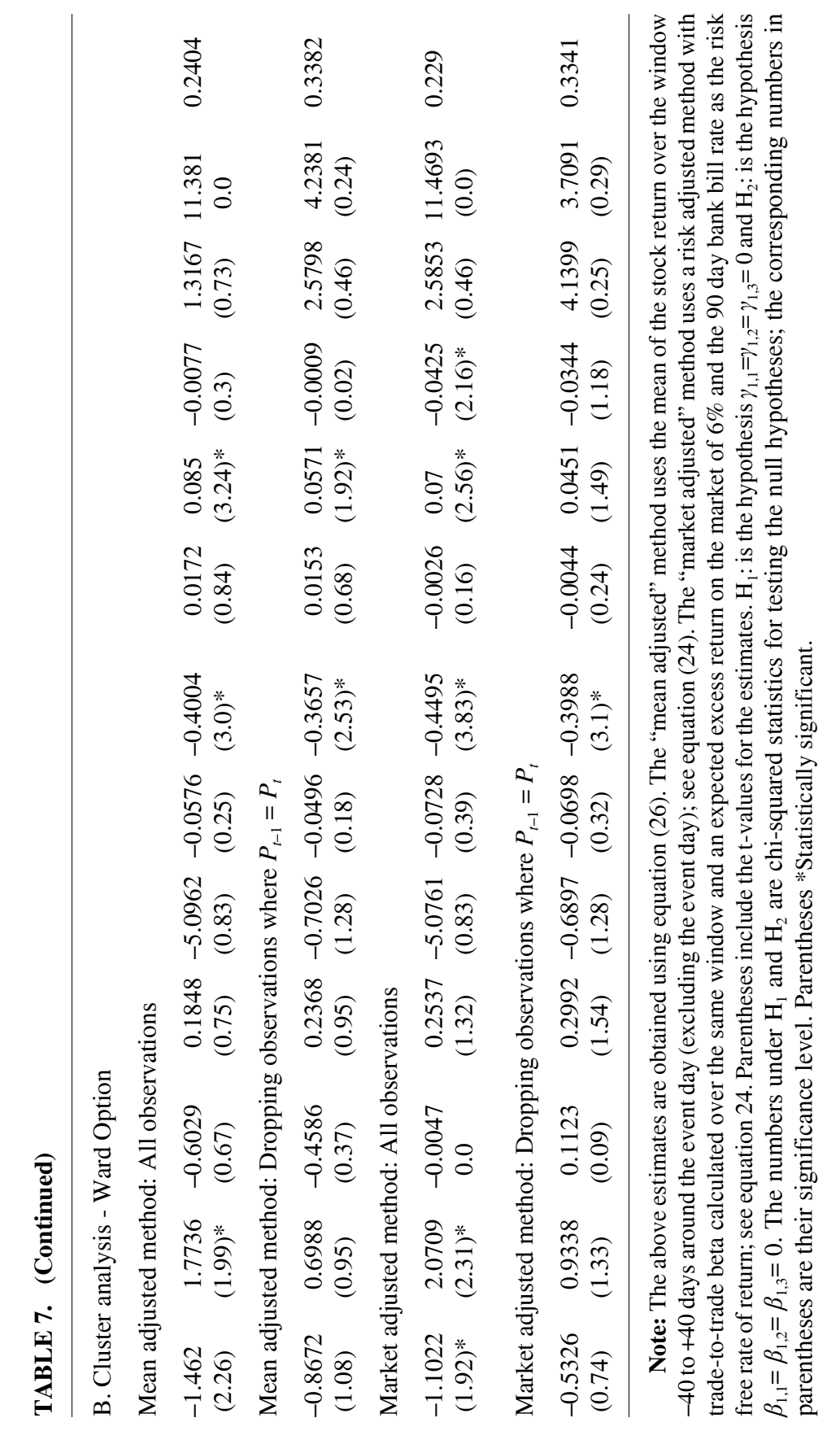


mixed traders since the option value $\beta_{2}$ is mostly significant. The lack of significance of and $\gamma_{1, i}$ and $\beta_{1}$ (in most cases) suggests that cluster one represents long term investors. There is evidence in favor of mixed and passive traders generating a separating equilibrium and no evidence of the existence of strictly active traders when the Flexible clustering option is used.

For the Ward clustering option $\gamma_{2}$ is again consistently significant lending support to the overall model, and is consistently insignificant. This supports the finding from the Flexible clustering option that strictly active traders were not present. $\beta_{1}$ is consistently insignificant suggesting that cluster one is dominated by passive or long term traders. $\beta_{2}$ is significant in most cases suggesting that cluster two is dominated by mixed traders. Finally, cluster three $\beta_{3}$ is significant with the wrong sign when the market adjusted drop measure is used for the large sample, a result somewhat difficult to interpret. Overall, the Ward option also suggests the presence of two types of investors namely passive or long term traders and mixed traders and provides no evidence of strictly active traders. This is consistent with table 7 and the Flexible option.

Finally, the existence of the active and mixed traders was tested for by linear restrictions on the parameters. If none of the clusters represent active traders, then none of the $\gamma_{1, i}$ are significant. Thus the following hypothesis can be tested:

$$
\mathrm{H}_{1} \text { : no active traders, or } \gamma_{1,1}=\gamma_{1,2}=\gamma_{1,3}=0
$$

The evidence from table 7 shows that this hypothesis cannot be rejected regardless of the clustering method and drop measure used. This supports the results from the above. If all active traders are able to keep two books, they would prefer to do so as this represents a tax option to them. Thus, an "active" trading strategy is carried out by mixed traders. The next hypothesis, therefore, is to test whether or not mixed investors are present in the market. If no mixed investors are present, none of the $\beta$ s are significant. This can be tested in the following way:

$$
\mathrm{H}_{2} \text { : no mixed trader hypothesis, or } \beta_{1,1}=\beta_{1,2}=\beta_{1,3}=0
$$

From table 7 there is evidence that this hypothesis is rejected regardless of the Cluster method used. Thus, it appears that mixed investors are present in the market, again supporting the results above. 


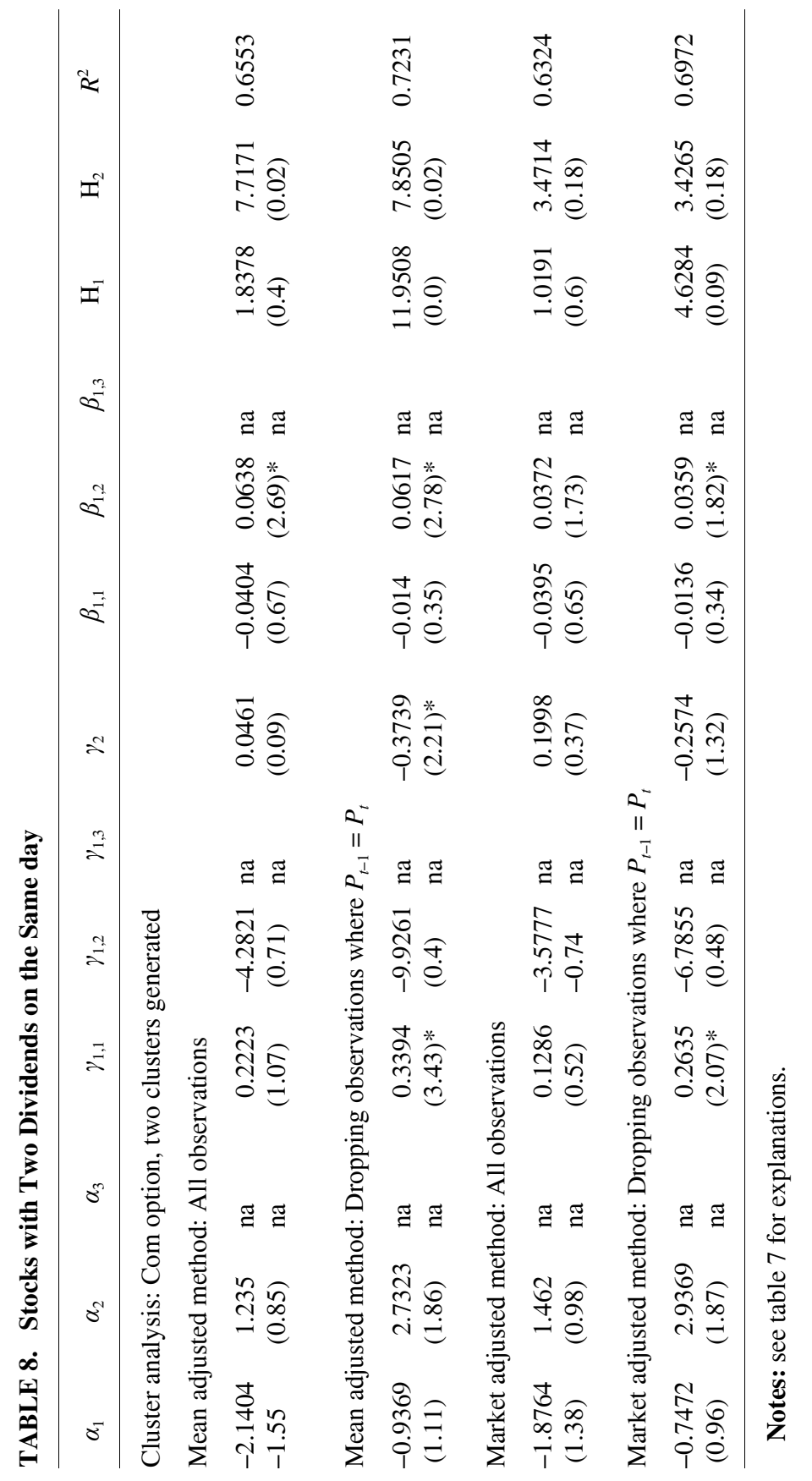


The general conclusion is that marginal investors were never strictly active traders, but that both mixed and strictly passive investors were marginal traders for different types of shares in the New Zealand share market in the period covered by the research.

Table 8 reports the results for the shares with two dividends on the same day. Due to the small sample size, none of the parameters are estimated with high confidence. The only set of results which produced a significant value for $\gamma_{2}$ was the average adjusted price drop for the sample with dropped observations. In that case the capital gains tax value was significant for cluster one while the option value was significant for cluster two. This suggests that active investors and mixed traders were attracted to these shares while passive investors were not. One possible rationale for this behavior is that the price drop would be expected to be larger for these shares than for those paying only taxable dividends. The price drop will be a tax deductible loss for active investors, but a non-deductible loss to passive investors.

\section{Summary and Conclusions}

This paper has developed a model of the pricing behavior for shares around the ex-dividend day based on the unique institutional characteristics of the New Zealand tax code between 1982 and 1985. The restrictions on short selling in place in New Zealand over the time period reinforced the possibility that different segments of the market were attractive to different types of traders as classified under the tax regime. The empirical results indicate that no single type of investor emerges as the marginal trader dominating all stocks; a dominating equilibrium. There is evidence, however, for a separating equilibrium in which passive, long term, investors emerge as the marginal traders in one segment while mixed traders, who can determine their tax status at the time of a share purchase, are the marginal traders in others.

\section{References}

Barclay, M.J. 1987. Dividends, taxes, and common stock prices: The ex-dividend day behavior of common stock prices before the income tax. Journal of Financial Economics 19: 31-44.

Bartholdy, J. and Brown, K. 1999. Ex-dividend day pricing in New Zealand. Accounting and Finance 39(2): 111-130. 
Bartholdy, J. and Riding, A. 1994. Thin trading and the estimation of betas on the New Zealand share market: The efficiency of alternative techniques. Journal of Financial Research 17(2): 241-254.

Booth, L.D. and Johnston, D.J. 1984. The ex-dividend day behavior of Canadian stock prices: Tax changes and clientele effects. Journal of Finance 39(2): 457-476.

Boyd, J.H. and Jagannathan, R. 1994. Ex-dividend price behavior of common stocks. Review of Financial Studies 7(4): 711-714.

Brown, P. and Walter, T. 1986. Ex-dividend day behavior of Australian share prices. Australian Journal of Management 11(2): 140-152.

Chay, J. B.; Marsden, A.; and Stubbs, R. 1995. Investment returns in the New Zealand market: 1931-1994. New Zealand Investment Analyst: 19-27.

Chui, A.; Strong, N.; and Cadle, J. 1992. The empirical significance of tax effects on the valuation of dividends: The UK evidence. Journal of Business Finance and Accounting 19(4): 515-532.

Eades, K. M.; Hess, P. J.; and. Kim, E. H. 1984. On interpreting security returns during the ex-dividend period. Journal of Financial Economics 13: 3-34.

Elton, E.J. and Gruber, M.J. 1970. Marginal stockholder tax rates and the clientele effect. Review of Economics and Statistics 52: 68-74.

Frank, M. and Jagannathan, R. 1998. Why do stock prices drop by less than the value of the dividend? Evidence from a country without taxes. Journal of Financial Economics (February): 161-188.

Hearth, D. and Rimbey, J.N. 1993. The dividend-clientele controversy and the tax reform act of 1986. Quarterly Journal of Business and Economics 32(1): 68-81.

Heath, D.C. and Jarrow, R.A. 1988. Ex-dividend stock price behavior and arbitrage opportunities. Journal of Business 61(1): 95-108.

Johnson, R.A. and Wichern, D.W. 1982. Applied Multivariate Statistical Analysis. Prentice Hall.

Kalay, A. 1982. The ex-dividend day behavior of stock prices: A re-examination of the clientele effect. Journal of Finance 37(4): 1059-1070.

Koski, J.L. and Scruggs, J. 1998. Who trades around the ex-dividend day? Evidence from NYSE audit file data. Financial Management 27(3): 58-72.

Lakonishok, J. and Vermaelen, T. 1983. Tax reform and ex-dividend day behavior. Journal of Finance 38(4): 1157-1179.

Lasfer, M.A. 1995. Ex-dividend behavior: Tax or short-term trading effects. Journal of Finance 50: 875-897.

Michaely, R. 1991. Ex-dividend day stock price behavior: The case of the 1986 tax reform act. Journal of Finance 46(3): 845-859.

Michaely, R. and Murgia, M. 1995. The effect of tax heterogeneity on prices and volume around the ex-dividend day: Evidence from the Milan stock exchange. Review of Financial Studies 8: 369-399.

Robin, A. 1991. The impact of the 1986 tax reform act on ex-dividend day returns. Financial Management 20(1): pp. 60-70.

SAS/STAT User's Guide, Volume 1, Version 6, SAS Institute. 